\title{
Growth of malignant extracranial tumors alters microRNAome in the prefrontal cortex of TumorGraft mice
}

\author{
Anna Kovalchuk ${ }^{1,4}$, Yaroslav Ilnytskyy², Rocio Rodriguez-Juarez ${ }^{2}$, Amanda Katz ${ }^{3}$, \\ David Sidransky ${ }^{3}$, Bryan Kolb ${ }^{1}$ and Olga Kovalchuk ${ }^{2}$ \\ 1 Department of Neuroscience, University of Lethbridge, Lethbridge, AB, Canada \\ 2 Department of Biological Sciences, University of Lethbridge, Lethbridge, $A B$, Canada \\ ${ }^{3}$ Department of Oncology, Champions Oncology, Baltimore, MD, USA \\ ${ }^{4}$ Leaders in Medicine Program, Cumming School of Medicine, University of Calgary, Calgary, AB, Canada \\ Correspondence to: Bryan Kolb, email:kolb@uleth.ca \\ Olga Kovalchuk, email: olga.kovalchuk@uleth.ca \\ Keywords: chemo brain, tumor brain, epigenetics, microRNA, Gerotarget \\ $\begin{array}{lll}\text { Received: April 04, } 2017 \quad \text { Accepted: April 27, } 2017 & \text { Published: August 03, } 2017\end{array}$ \\ Copyright: Kovalchuk et al. This is an open-access article distributed under the terms of the Creative Commons Attribution License 3.0 (CC \\ BY 3.0), which permits unrestricted use, distribution, and reproduction in any medium, provided the original author and source are credited.
}

\section{ABSTRACT}

A wide array of central nervous system complications, neurological deficits, and cognitive impairments occur and persist as a result of systemic cancer and cancer treatments. This condition is known as chemo brain and it affects over half of cancer survivors. Recent studies reported that cognitive impairments manifest before chemotherapy and are much broader than chemo brain alone, thereby adding in tumor brain as a component. The molecular mechanisms of chemo brain are underinvestigated, and the mechanisms of tumor brain have not been analyzed at all. The frequency and timing, as well as the long-term persistence, of chemo brain and tumor brain suggest they may be epigenetic in nature. MicroRNAs, small, single-stranded non-coding RNAs, constitute an important part of the cellular epigenome and are potent regulators of gene expression. miRNAs are crucial for brain development and function, and are affected by a variety of different stresses, diseases and conditions. However, nothing is known about the effects of extracranial tumor growth or chemotherapy agents on the brain microRNAome.

We used the well-established TumorGraft TM mouse models of triple negative (TNBC) and progesterone receptor positive ( $P R+B C)$ breast cancer, and profiled global microRNAome changes in tumor-bearing mice upon chemotherapy, as compared to untreated tumor-bearing mice and intact mice. Our analysis focused on the prefrontal cortex (PFC), based on its roles in memory, learning, and executive functions, and on published data showing the PFC is a target in chemo brain.

This is the first study showing that tumor presence alone significantly impacted the small RNAome of PFC tissues. Both tumor growth and chemotherapy treatment affected the small RNAome and altered levels of miRNAs, piRNAs, tRNAs, tRNA fragments and other molecules involved in post-transcriptional regulation of gene expression. Amongst those, miRNA changes were the most pronounced, involving several miRNA families, such as the miR-200 family and miR-183/96/182 cluster; both were deregulated in tumor-bearing and chemotherapy-treated animals. We saw that miRNA deregulation was associated with altered levels of brain-derived neurotrophic factor (BDNF), which plays an important role in cognition and memory and is one of the known miRNA targets. BDNF downregulation has been associated with an array of neurological conditions and could be one of the mechanisms underlying tumor brain 


\section{and chemo brain. In the future our study could serve as a roadmap for further analysis of cancer and chemotherapy's neural side effects, and differentially expressed miRNAs should be explored as potential tumor brain and chemo brain biomarkers.}

\section{INTRODUCTION}

Initial reports on the cognitive changes associated with cancer chemotherapies appeared in the late 1970s to the mid-1980s, but received scientific attention starting only in the mid-1990s. Several studies reported significant cognitive changes in cancer survivors [1]. These changes included problems with concentration, learning and memory, and executive functions. Central nervous system (CNS) toxicity manifestations had major negative effects on patient's quality of life. Most of the chemotherapyinduced cognitive deficits were reported in breast cancer patients, in which deficits affected up to $50 \%$ of survivors and lasted for more than 10 years [2]. These effects were so significant that breast cancer survivors even coined a term for them - "chemo fog" or "chemo brain" $[3,4]$. The latter term is now widely accepted and used to describe the CNS toxicity of chemotherapy (reviewed in [3-5]). A large-scale study following 200 breast cancer survivors for 21 years post chemotherapy reported on the longterm persistence of changes in executive functioning, verbal memory, and processing speed; likewise, they saw reductions of grey matter volume, and changes in white matter microstructural integrity [6-8]. While the majority of chemo brain reports come from the analysis of breast cancer survivor cohorts, chemo brain has also been reported in lymphoma, leukemia, lung, gastrointestinal, and other cancers, and has been accepted as a form of general post-chemotherapy CNS toxicity $[4,9]$.

The clinical analysis of chemo brain's molecular mechanisms is complicated due to varying treatment protocols, significant inter-patient variability (as a result of co-morbidities), and various other factors [1012]. Hence, the majority of chemo brain mechanistic studies used cell lines and rodent models (reviewed in $[13,14])$, to determine that chemotherapy caused oxidative stress, suppressed neuronal proliferation and differentiation, induced apoptosis, affected the levels of histone modification and chromatin remodeling, caused the aberrant expression of genes, and altered the levels of neurotrophic and neurogenic proteins [1517]. These molecular changes were associated with altered neurogenesis and deficits in learning and memory processes [16, 18-20].

Recent studies reported that cognitive impairments manifest before chemotherapy in $20 \%-30 \%$ of breast cancer patients and that these phenomena might be much broader than chemo brain alone. They may instead constitute both cancer and cancer treatment-associated cognitive changes reviewed in [5], thereby adding in the tumor brain component. While these studies provided significant insights into chemo brain, much remains to be learned about its molecular and cellular mechanisms. The molecular mechanism of tumor brain has not been analyzed at all.

The frequency and timing, as well as the long-term persistence, of chemo brain and tumor brain suggest they are epigenetic in nature. Epigenetic changes encompass meiotically heritable and mitotically stable alterations that regulate gene expression and genome stability; these include DNA methylation, histone modification, and noncoding RNA regulation [21]. Among small non-coding RNAs, microRNAs (miRNAs) are the most studied. MiRNA loci are transcribed by polymerase II, which gives rise to primary miRNA transcripts (pri-miRNAs). Portions of pri-miRNAs form hairpin structures that are cleaved and released by the action of ribonuclease Drosha, producing precursor miRNAs (pre-miRNAs). Next, premiRNAs are exported to the cytoplasm with the help of the Exportin 5 system, where the ribonuclease Dicer cleaves them, yielding mature single-stranded miRNA. Together with RNA-induced silencing complex (RISC) proteins such as Ago2, miRNAs interact with their associated mRNAs, thereby regulating the production of proteins. MiRNAs are crucial for brain development, neuronal differentiation, and axon regeneration following injury [22-25]. They regulate neuronal plasticity, and are likewise involved in the regulation of learning and memory [26-28]. Interestingly, miRNA deregulation was reported in autism [29], Alzheimer's and Parkinson's diseases, traumatic brain injury, stroke, amyotrophic lateral sclerosis, schizophrenia, and many other diseases and conditions [30-35]. Dicer and RISC proteins are important for brain development [36-38], and alterations in the expression of miRNA-processing machinery and RISC members are associated with brain diseases and conditions [3942]. Furthermore, miRNA-based therapies may provide novel approaches for the treatment of neurodegenerative diseases [43], and miRNA profiles constitute essential diagnostic and prognostic biomarkers of diseases and conditions [44-46]. Various stresses and exposures affect brain microRNAome [47-49]. However, nothing is known about the effects of extracranial tumor growth or chemotherapy agents on the brain microRNAome.

Analyzing these phenomena in tumor-bearing animals is needed to gain a full mechanistic understanding of both chemo brain and tumor brain. In a previous study, we analyzed gene expression and DNA methylation changes in the PFC tissues of triple negative breast cancer (TNBC) and progesterone positive breast cancer $(\mathrm{PR}+\mathrm{BC})$ mice. We noted that tumor growth caused changes in gene expression Aging, in press (2017). We used mouse TumorGraft ${ }^{\mathrm{TM}}$ models of untreated TNBC and $\mathrm{PR}+\mathrm{BC}$, as well as TNBC TumorGraft animals 
treated with Doxorubicin/ Cyclophosphamide/ Paclitaxel (TNBC/DCP) and PR+BC animals treated with Topotecan $(\mathrm{PR}+\mathrm{BC} / \mathrm{TOP})$ or Crizotinib $(\mathrm{PR}+\mathrm{BC} / \mathrm{CRIZ})$ to analyze the roles of miRNAs in tumor brain and chemo brain.

Here we report that extracranial malignant tumor growth had a profound effect on the microRNAome of the prefrontal cortex of experimental animals and caused changes in the levels of the miRNA processing machinery protein Ago2. Chemo and tumor brain-induced miRNA changes involved several miRNA families, such as the miR-200 family and miR-183/96/182 cluster, which were deregulated in $\mathrm{PR}+\mathrm{BC}$ tumor-bearing and chemotherapytreated animals. MiRNA deregulation was associated with altered levels of BDNF (brain-derived neurotrophic factor), a miRNA target that plays a key role in cognition and memory. Furthermore, deregulated miRNAs may serve as biomarkers of tumor brain and chemo brain.

\section{RESULTS}

\section{Descriptive statistics of the next generation sequencing (NGS)}

The NGS approach offers excellent technological opportunities to capture the entire repertoire of small RNAs and conduct a comprehensive analysis of the small RNAome [50].A total of 3853355, 3061761, 5573723, 4534609, 4291129, and 3808590 mappable reads were detected from the intact control, TNBC, $\mathrm{PR}+\mathrm{BC}, \mathrm{TNBC} /$ $\mathrm{DCP}, \mathrm{PR}+\mathrm{BC} / \mathrm{CRIZ}$, and $\mathrm{PR}+\mathrm{BC} / \mathrm{TOP}$ animal samples, respectively. These were mapped to various classes of noncoding RNAs (miRNAs, piRNAs, snoRNAs, snRNAs, rRNAs, and tRNAs) (Table 1). MicroRNAs constituted the largest part of the small RNA pool, reaching $81.7,77.8$,

A

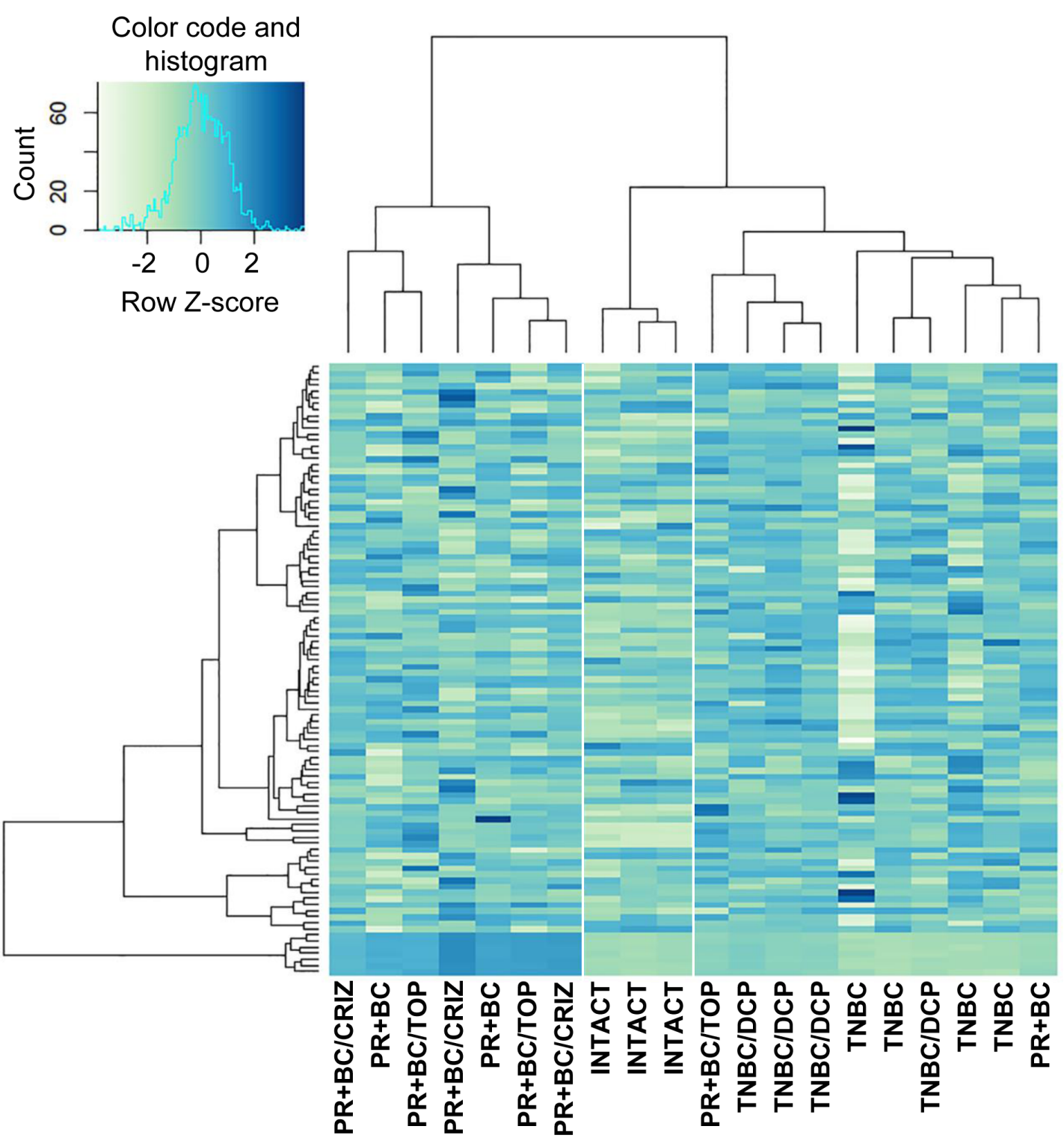



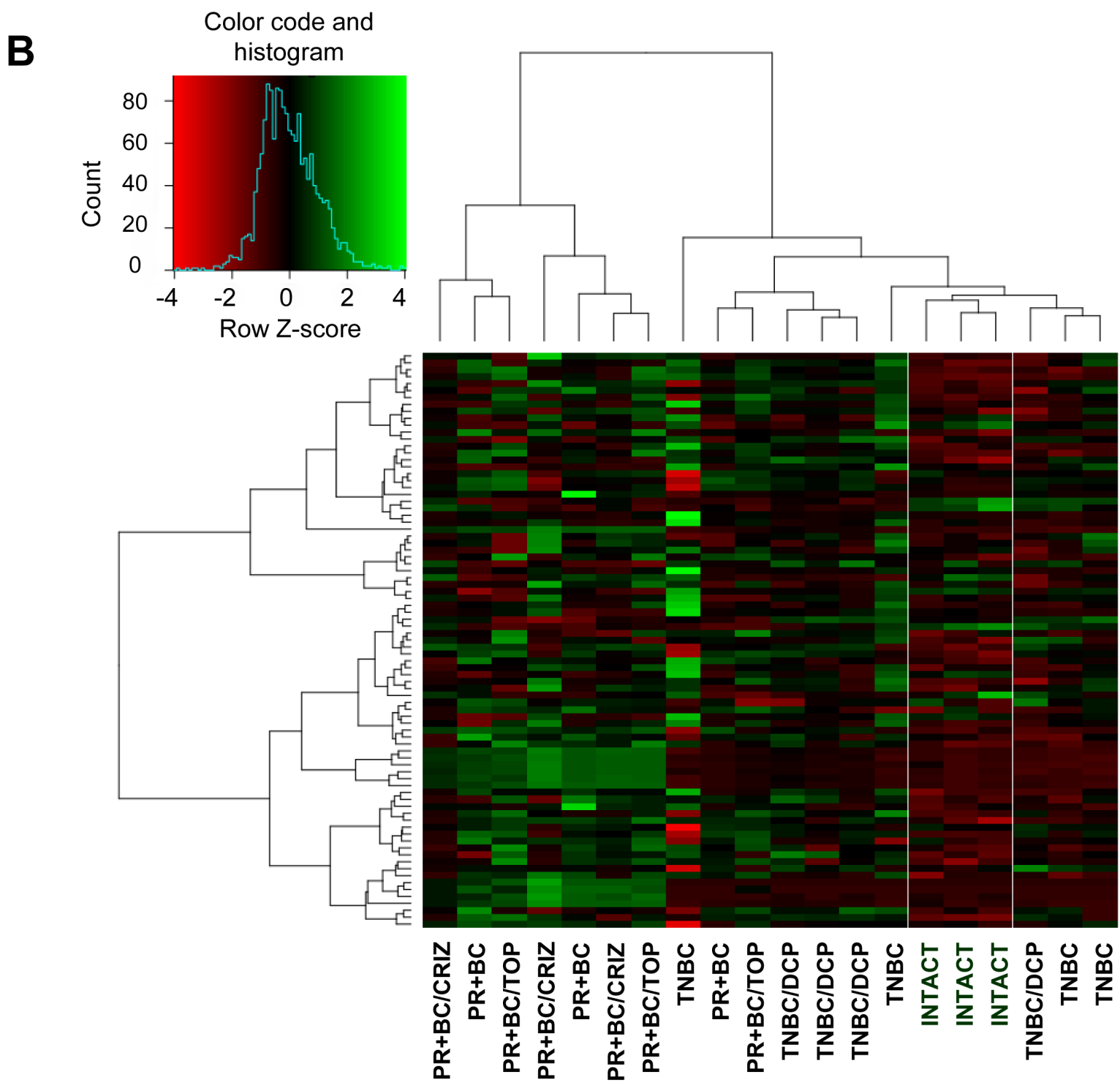

Figure 1: Next generation sequencing-based analysis of small RNA expression in the PFC tissues of intact, TNBC and PR+BC-bearing chemotherapy-treated and untreated TumorGraft mice. A. Hierarchical clustering of all samples based on the entire small RNA profile. B. Hierarchical clustering of all samples based on the microRNAome profile.

$79.8,77.9,72.4$, and $82.1 \%$ of all small RNA molecules detected in intact controls, TNBC, PR+BC, TNBC/DCP, $\mathrm{PR}+\mathrm{BC} / \mathrm{CRIZ}$, and $\mathrm{PR}+\mathrm{BC} / \mathrm{TOP}$ samples, respectively (Table 1).

\section{Differential expression of miRNAs in the PFC tissues of tumor-bearing treated and untreated animals}

We identified all classes of differentially expressed (DE) small RNAs with a fold change $>2.0$ and a false discovery rate cut-off of 0.05 . Initial unsupervised hierarchical clustering was performed using all DE small
RNAs. We noted a distinct separation between intact control PFC tissues and PFC tissues of tumor-bearing animals (Figure 1A, Supplementary Figure 1). Next, we focused on DE miRNA analysis (fold change $>2.0$ and false discovery rate cut-off of 0.05 ) and performed unsupervised hierarchical clustering. Similar to the whole of the small RNAs, we noted a miRNA level-based separation of the intact controls from the samples of tumor-bearing treated and untreated animals, proving that generated miRNA signatures discriminate between sample types (Figure 1B).

While there was an apparent separation between the small RNA and miRNAome profiles of the PFC tissues of the intact control and TNBC- and PR+BC-bearing 
Table 1: Library composition

\begin{tabular}{|c|c|c|c|c|c|c|}
\hline \multicolumn{7}{|c|}{ Absolute composition } \\
\hline CATEGORY & INTACT & TNBC & TNBC/DPC & $\mathbf{P R}+\mathbf{B C}$ & $\mathrm{PR}+\mathrm{BC} / \mathrm{TOP}$ & $\begin{array}{l}\mathrm{PR}+\mathrm{BC} / \\
\text { CRIZ }\end{array}$ \\
\hline number of samples & 3 & 4 & 4 & 3 & 3 & 3 \\
\hline total & 3853355 & 3061761 & 5573723 & 4534609 & 4291129 & 3808590 \\
\hline miRNA & 3148510 & 2420296 & 4457646 & 3537230 & 3108049 & 3125959 \\
\hline snoRNA & 32438 & 20672 & 37850 & 30798 & 26334 & 24089 \\
\hline snRNA & 1422 & 1516 & 2806 & 2314 & 2524 & 1720 \\
\hline rRNA & 21921 & 16848 & 29983 & 22662 & 21086 & 18516 \\
\hline tRNA & 108118 & 176533 & 246617 & 276325 & 497035 & 145168 \\
\hline piRNA & 30690 & 20876 & 38425 & 32886 & 30772 & 28125 \\
\hline exons & 196436 & 160890 & 322187 & 265234 & 247267 & 180506 \\
\hline repats & 42549 & 27304 & 50582 & 36629 & 35009 & 32587 \\
\hline introns & 30529 & 25988 & 47328 & 40121 & 39528 & 28231 \\
\hline unclassified & 22427 & 15676 & 30110 & 24959 & 22658 & 19392 \\
\hline no_match & 218315 & 175162 & 310189 & 265451 & 260867 & 204297 \\
\hline \multicolumn{7}{|c|}{ Relative composition } \\
\hline CATEGORY & INTACT & TNBC & TNBC/DPC & $\mathbf{P R}+\mathbf{B C}$ & $\mathrm{PR}+\mathrm{BC} / \mathrm{TOP}$ & $\begin{array}{l}\text { PR+BC/ } \\
\text { CRIZ }\end{array}$ \\
\hline Total $\%$ & 100.0 & 100.0 & 100.0 & 100.0 & 100.0 & 100.0 \\
\hline miRNA & 81.7 & 77.8 & 79.8 & 77.9 & 72.4 & 82.1 \\
\hline snoRNA & 0.8 & 0.6 & 0.7 & 0.7 & 0.6 & 0.6 \\
\hline snRNA & 0.0 & 0.1 & 0.1 & 0.1 & 0.1 & 0.1 \\
\hline rRNA & 0.6 & 0.6 & 0.5 & 0.5 & 0.5 & 0.5 \\
\hline tRNA & 2.8 & 6.5 & 4.5 & 6.2 & 11.5 & 3.6 \\
\hline piRNA & 0.8 & 0.7 & 0.7 & 0.7 & 0.7 & 0.8 \\
\hline exons & 5.1 & 5.5 & 5.8 & 5.9 & 5.8 & 4.7 \\
\hline repats & 1.1 & 0.9 & 0.9 & 0.8 & 0.8 & 0.9 \\
\hline introns & 0.8 & 0.9 & 0.9 & 0.9 & 0.9 & 0.8 \\
\hline unclassified & 0.6 & 0.5 & 0.5 & 0.6 & 0.5 & 0.5 \\
\hline no_match & 5.7 & 5.8 & 5.6 & 5.9 & 6.1 & 5.4 \\
\hline
\end{tabular}

animals, profiles of the PFC samples of tumor-bearing treated animals differed only from those of intact controls and not from the tumor-bearing untreated animals. Amongst samples, TNBC samples clustered better than the $\mathrm{PR}+\mathrm{BC}$ samples. These differences may depend upon tumour transplantation, positioning and growth in each individual animal and host responses.

Furthermore, sample clustering revealed they are primarily distinguished by the relative expression of a common set of miRNAs (Figure 1B). To gain further insight into the differentially expressed miRNAs and their potential roles in chemo brain and tumor brain, we proceeded to analyze and compare miRNAs that were differentially expressed in various experimental groups.

NGS data revealed that the presence of a malignant extracranial tumor alone had a major effect on the miRNAome. We found that 5 miRNAs were up-regulated in the PFC tissues of TNBC bearing mice, as compared to intact controls. In the PFC tissues of $\mathrm{PR}+\mathrm{BC}$ bearing mice, 33 miRNAs were up-regulated, and 4 miRNAs were down-regulated. Among those, miR-191-5p was up-regulated in both $\mathrm{TNBC}$ and $\mathrm{PR}+\mathrm{BC}$ tumor-bearing groups (Figure 2).

Treatment of TNBC animals with the DCP regimen led to the upregulation of 18 and downregulation of 2 miRNAs in the PFC tissues of tumor-bearing treated animals. Two miRNAs (miR-191-5p and miR-100-5p) were up-regulated in TNBC and TNBC/DCP animals, as compared to intact controls (Figure 3). Interestingly, no differential miRNA expression was detected between TNBC tumor-bearing treated and untreated animals.

The growth of $\mathrm{PR}+\mathrm{BC}$ and subsequent chemotherapy treatments also affected the miRNAome profiles of PFC tissues of TumorGraft mice. There, 
treatment of $\mathrm{PR}+\mathrm{BC}$ animals with crizotinib led to the upregulation of 13 microRNAs in the PFC tissues of experimental animals, as compared to intact controls. Topotecan treatment led to the upregulation of 37 and downregulation of 7 miRNAs (Figure 4).
We noted a commonality between all three groups $(\mathrm{PR}+\mathrm{BC}, \mathrm{PR}+\mathrm{BC} / \mathrm{CRIZ}$, and $\mathrm{PR}+\mathrm{BC} / \mathrm{TOP}): \mathrm{miR} 200$ family (miR-200a, miR-200b, miR-200c, miR-141, and miR-429), miR-183/96/182 cluster, miR-30d-5p, and miR-191-5p were up-regulated, as compared to intact

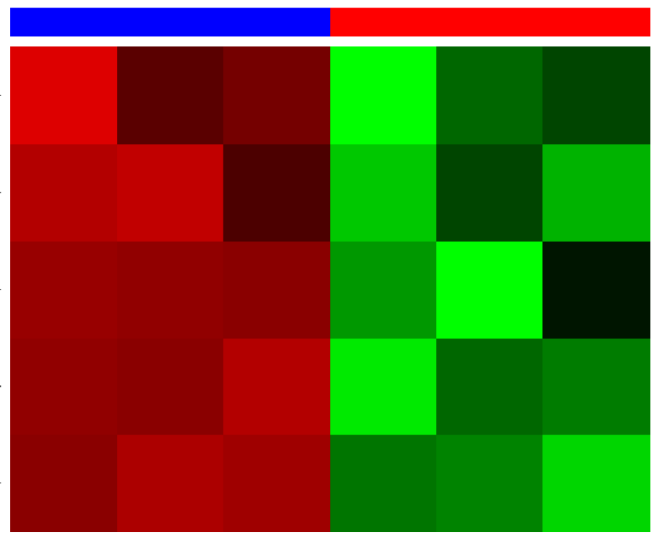

INTACT
TNBC

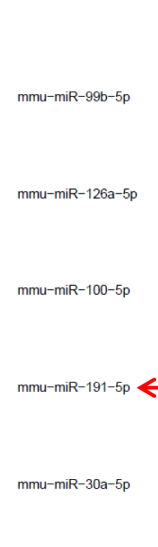

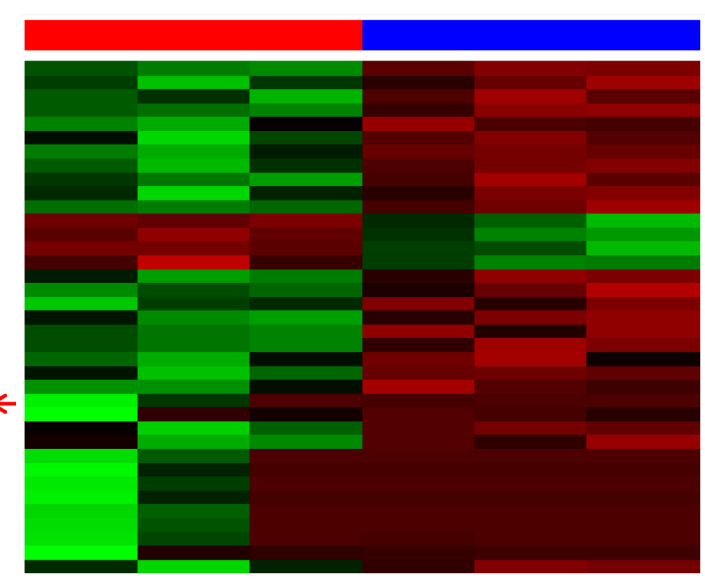

PR+BC

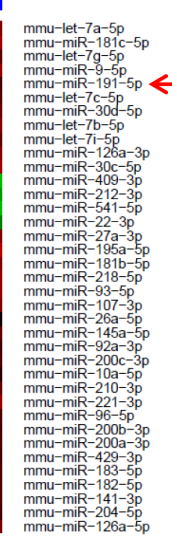

INTACT

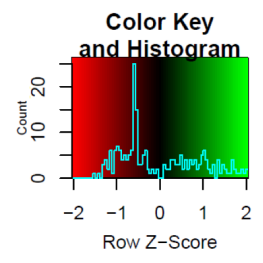

Figure 2: Heatmaps of microRNAs differentially expressed in the PFC tissues of the TNBC and PR+BC tumor bearing animals as compared to intact controls. Red arrow indicates miRNAs commonly regulated in both groups.

UNTREATED

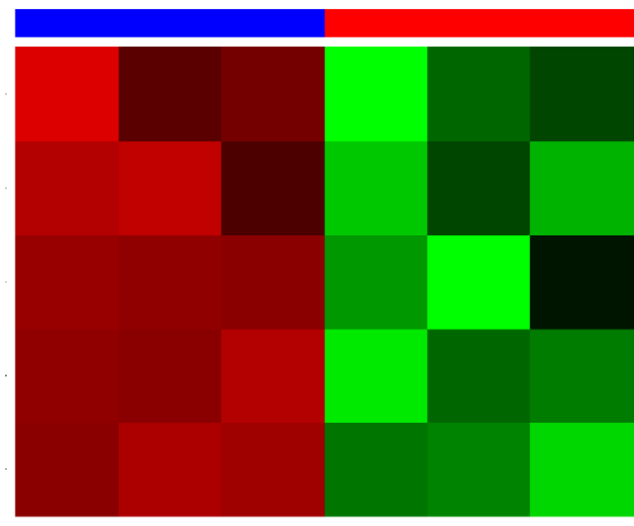

INTACT

TNBC

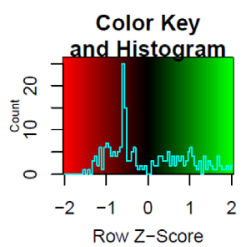

Figure 3: Heatmaps of microRNAs differentially expressed in the PFC tissues of the TNBC untreated and TBNC/DCP mice as compared to intact controls. Red arrows indicate miRNAs commonly regulated in both groups. 
controls. Moreover, miRNAs of the let-7 family were up-regulated in the PFC tissues of $\mathrm{PR}+\mathrm{BC}$ untreated and crizotinib-treated animals as compared to intact controls. MiR-409-3p and miR-22-3p were down-regulated in the PFC tissues of the PR $+\mathrm{BC}$ untreated and crizotinib-treated $\mathrm{PR}+\mathrm{BC}$ animals. Similar to the TNBC TumorGraft mice, no differential miRNA expression was identified between $\mathrm{PR}+\mathrm{BC}$ tumor-bearing treated and $\mathrm{PR}+\mathrm{BC}$ tumor-bearing untreated mice.

\section{Altered levels of BDNF in the PCF tissues of tumor-bearing treated and untreated animals}

MiR-191-5p was up-regulated in all animal groups. Interestingly, miR-191 was recently reported to be a regulator of brain-derived neurotrophic factor (BDNF) [51]. BDNF is a member of the nerve growth factor family and one of the fundamental factors regulating neuronal growth, maturation and survival in the brain and spinal cord [52]. Among the other miRNAs, the miR-183/96/182 family and miR-10b target BDNF as well $[51,53]$. With this in mind, using western immunoblotting, we analyzed the levels of BDNF in the PFC tissues of intact controls, and $\mathrm{TNBC}$ and $\mathrm{PR}+\mathrm{BC}$ tumor-bearing treated and untreated mice.

BDNF levels were significantly decreased in the PFC tissues of PR+BC TumorGraft animals $(p=0.00006)$ and in $\mathrm{PR}+\mathrm{BC} / \mathrm{TOP}$ and $\mathrm{PR}+\mathrm{BC} / \mathrm{CRIZ}(p=0.0192$ and $p=0.0050$, respectively), as compared to intact controls. Moreover, levels of BDNF in the PFC tissues of PR $+\mathrm{BC} /$ $\mathrm{CRIZ}$ were also significantly decreased, as compared to untreated $\mathrm{PR}+\mathrm{BC}$ animals $(p=0.0011)$. In the untreated TNBC cohort, BDNF levels exhibited a trend to decrease (90\% confidence level). No significant change was observed in the TNBC/DPC animals, albeit a downregulation trend was noted $(p<0.10)$ (Figure 5).
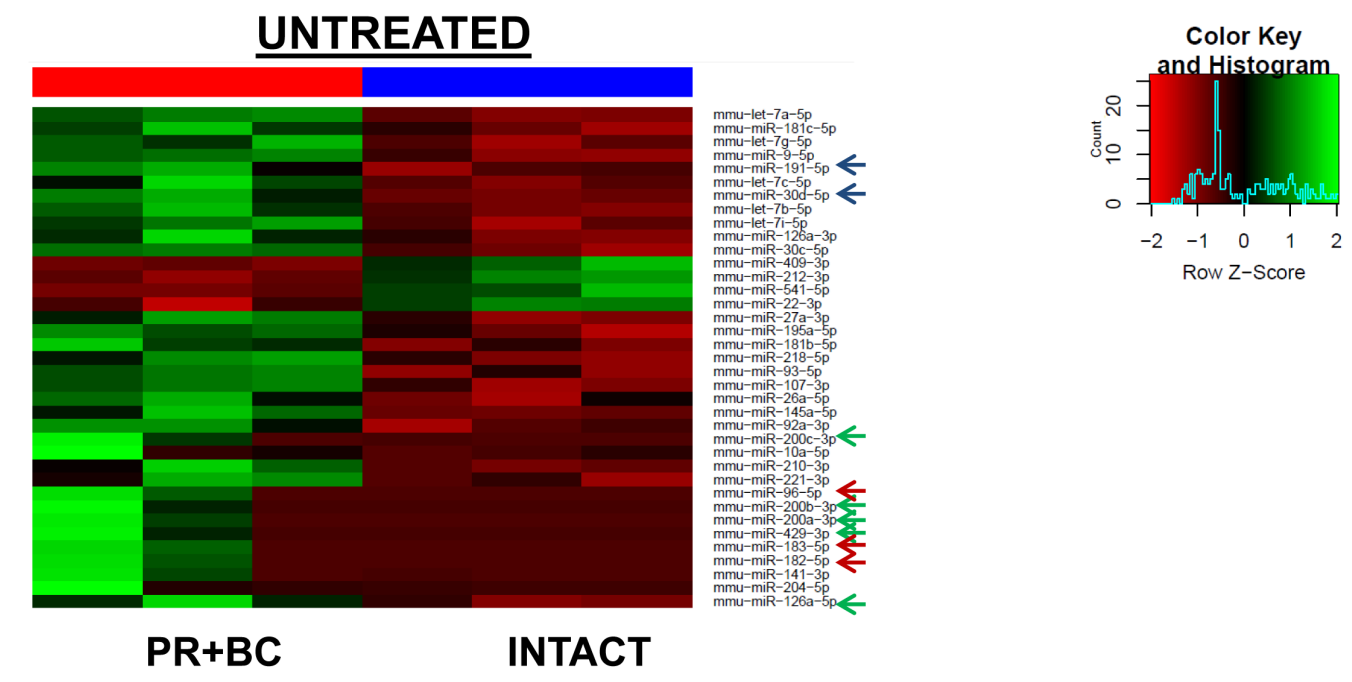

TREATED - CRIZOTINIB

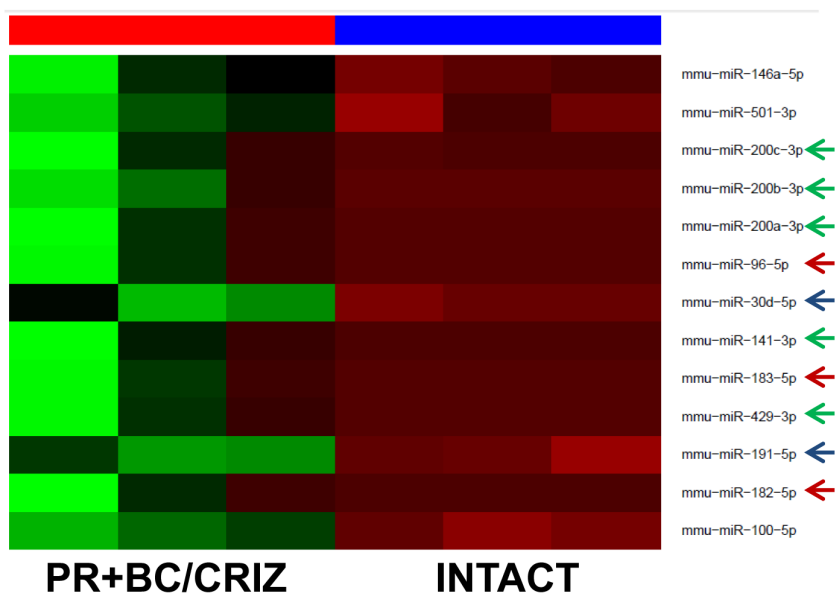

\section{TREATED - TOPOTECAN}
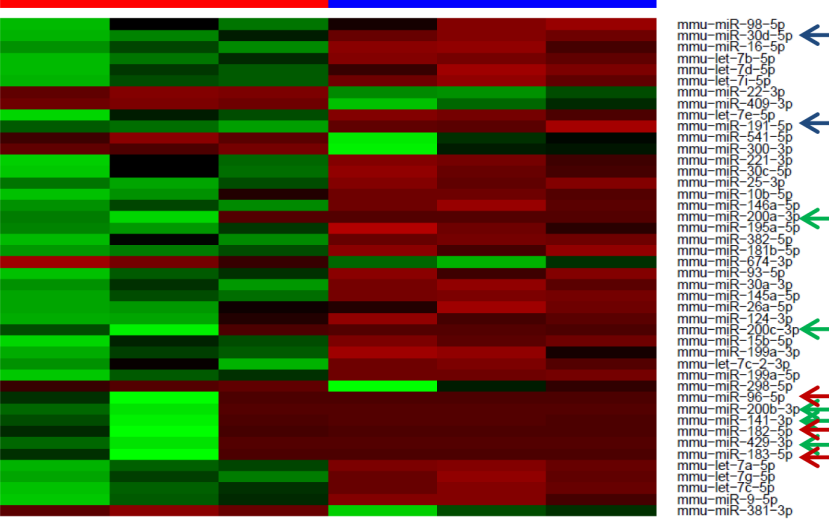

$\mathrm{PR}+\mathrm{BC} / \mathrm{TOP}$
INTACT

Figure 4: Heatmaps of microRNAs differentially expressed in the PFC tissues of the PR+BC untreated, PR+BC/CRIZ and $\mathrm{PR}+\mathrm{BC} / \mathrm{TOP}$ mice as compared to intact controls. Arrows indicate miRNAs commonly regulated in both groups. Green arrow - miR-200 family; blue arrow - miR-183/96/182 cluster; red arrow - other common miRNAs. 
MiRNA processing machinery in the PCF tissues of tumor-bearing treated and untreated animals

To determine the possible mechanisms of aberrant miRNAome changes, we analyzed the levels of Dicer and Ago2 proteins - members of small RNA processing machinery. While no statistically significant changes were noted in the levels of Dicer, levels of Ago2 were significantly up-regulated in the PFC tissues of untreated $\mathrm{PR}+\mathrm{BC}$ TumorGraft animals $(p=0.0010)$ and in $\mathrm{PR}+\mathrm{BC} /$ TOP and PR+BC/CRIZ $(p=0.00005$ and $p=0.0020$, respectively) (Figure 6).

\section{DISCUSSION}

This is the first in-depth analysis of microRNAome profiles in PFC tissues of chemotherapy treated and untreated mouse TumorGraft ${ }^{\mathrm{TM}}$ models of triple negative and progesterone receptor positive breast cancer. We saw that the growth of TNBC and PR+BC tumors affects the miRNAome.

While a large body of evidence has accumulated on the incidence of cancer and cancer treatment-related cognitive changes (tumor brain and chemo brain), there is still a lot to learn about their molecular mechanisms. As

$\underline{\text { TNBC }}$
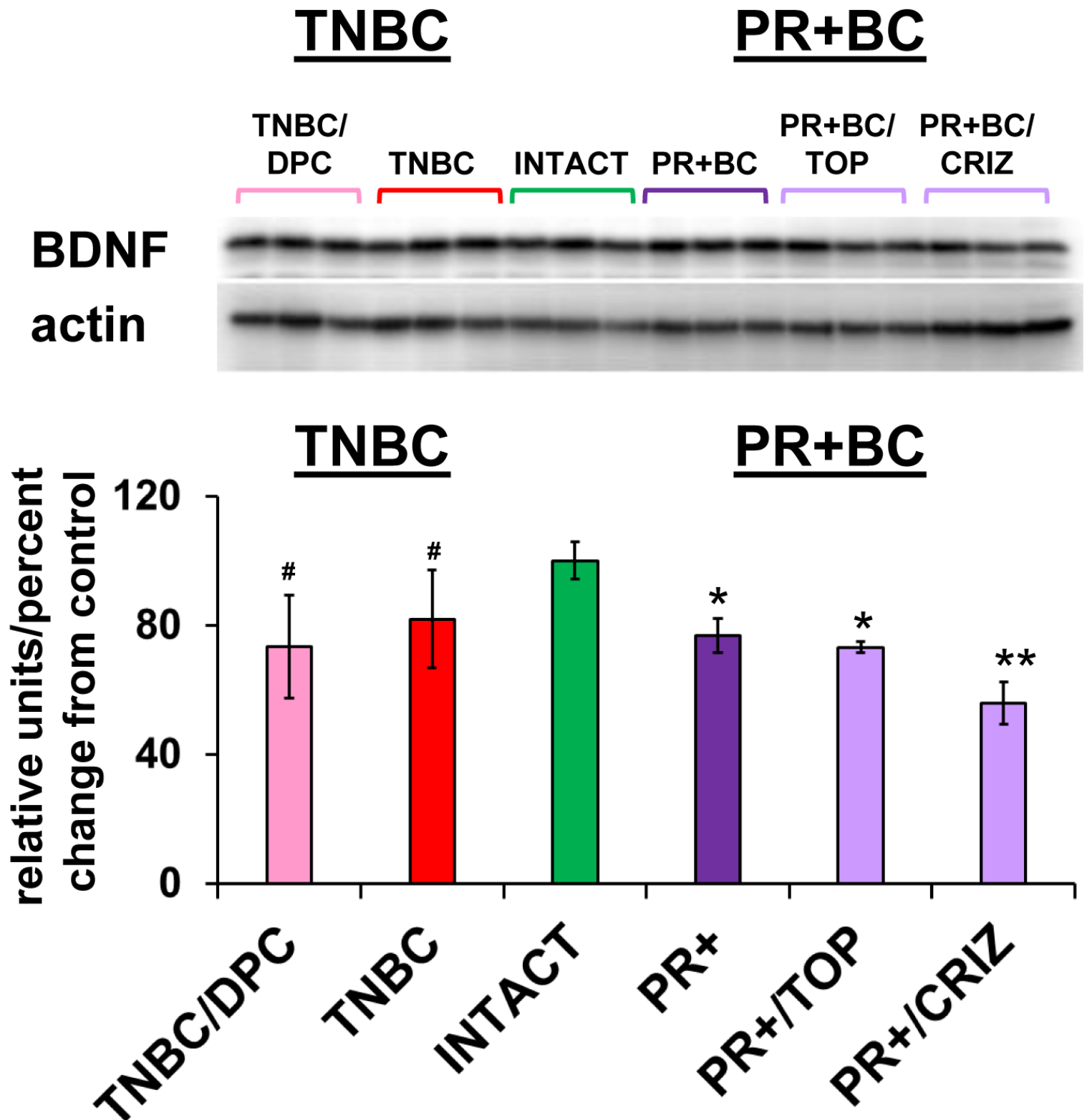

Figure 5: Levels of BDNF in the PFC tissues of intact and TNBC and PR+BC-bearing chemotherapy treated and untreated TumorGraft mice. Data are shown as relative units/percent change from control. Due to protein size differences and scarcity of tissue membranes were re-used several times in context of a large scale study. $\# p<0.10 ; * p<0.05 ; * * p<0.01$. 
per the timing and long-term persistence of tumor brain and chemo brain, these phenomena might be epigenetic in nature and based on altered gene expression patterns affecting brain function.

Epigenetic changes governing alterations in gene expression include DNA methylation, histone modification, and small RNA-associated silencing. Amongst the latter, miRNAs (evolutionarily conserved, small, single-stranded RNA molecules that operate as main negative gene regulators) are of special interest and significance. MiRNAs are important in brain development and in all CNS functions and processes. They regulate cellular proliferation, differentiation, repair and death, and take part in inflammatory responses. Aberrant expression of miRNAs underlies a wide array of neurological and psychiatric diseases, such as Alzheimer's, Parkinson's, and Huntington's, stroke, traumatic brain injury, amyotrophic lateral sclerosis, autism, schizophrenia, and brain tumors [54].

Even so, nothing is known about the role of miRNAs in the brain's response to the combination of malignant non-CNS tumor growth and subsequent chemotherapy. This is the first study to analyze miRNA changes in tumor brain and chemo brain. We showed that TNBC and $\mathrm{PR}+\mathrm{BC}$ tumor growth and presence significantly altered the miRNAome in the PFC tissues of TumorGraft animals. The PFC is a key regulatory region that receives input from all other cortical areas, and serves to coordinate executive function, motor, cognitive, and social behaviors, attention, and working memory $[55,56]$.

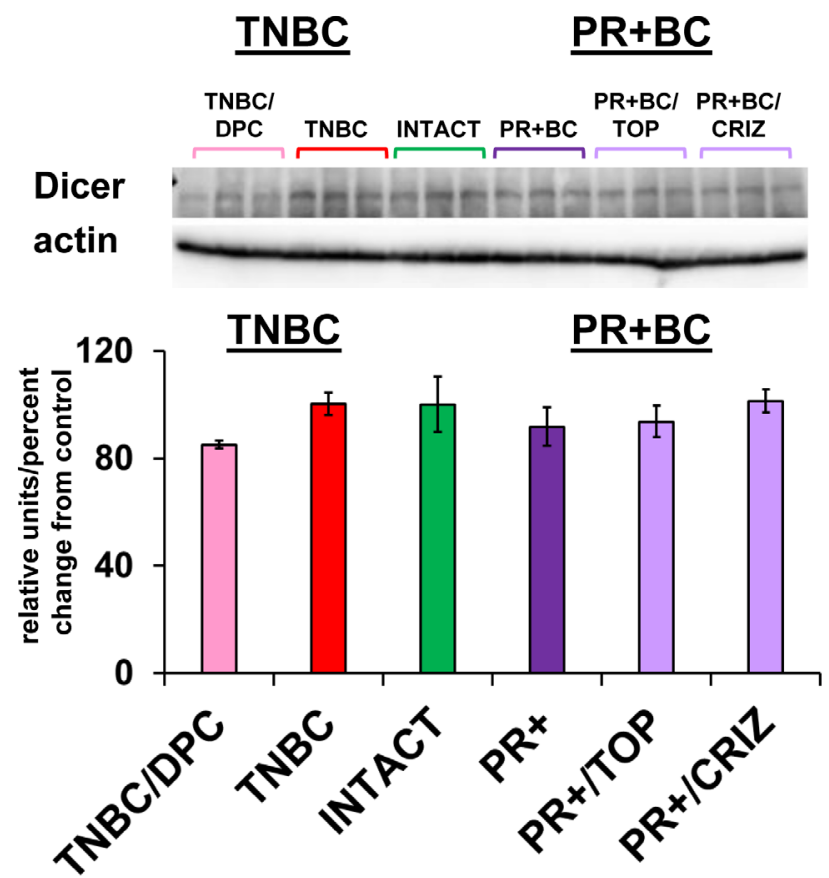

While tumor growth-related miRNAome changes were observed in the PFC tissues of both breast cancer groups, they were more pronounced in the PFC tissues of $\mathrm{PR}+\mathrm{BC}$-bearing animals than in TNBC-bearing ones. The reasons behind these changes and their molecular mechanisms, along with potential cellular changes and behavioral repercussions need to be further studied and analyzed, and may depend upon the biology of tumors as well as chemotherapy responsiveness. Chemotherapy treatment of TNBC and $\mathrm{PR}+\mathrm{BC}$-bearing animals led to further alterations in the miRNAome, and amongst differentially expressed miRNAs, miR-191-5p was upregulated in all experimental groups (tumor-bearing treated and untreated groups, as compared to intact controls). While this miRNA has not been extensively researched, some studies have reported that miR-191-5p was up-regulated in major depressive disorders and downregulated in Alzheimer's disease (AD) [57]. This miRNA is commonly down-regulated in the blood and plasma of $\mathrm{AD}$ patients and is considered to be a circulating $\mathrm{AD}$ biomarker [58]. Overall, miRNA expression patterns in the blood and brain do not always fully correlate. Therefore, it would be interesting to analyse the levels of miR-191-5p in the plasma and whole blood of tumor brain and chemo brain animals. This would help to better discern miR-1915 p's roles in tumor brain and chemo brain as a potential molecular driver and biomarker of the two phenomena. Likewise, it would help determine if there exists any longdistance signalling between the tumor and the brain that involves miR-191-5p or any other mRNAs. New studies
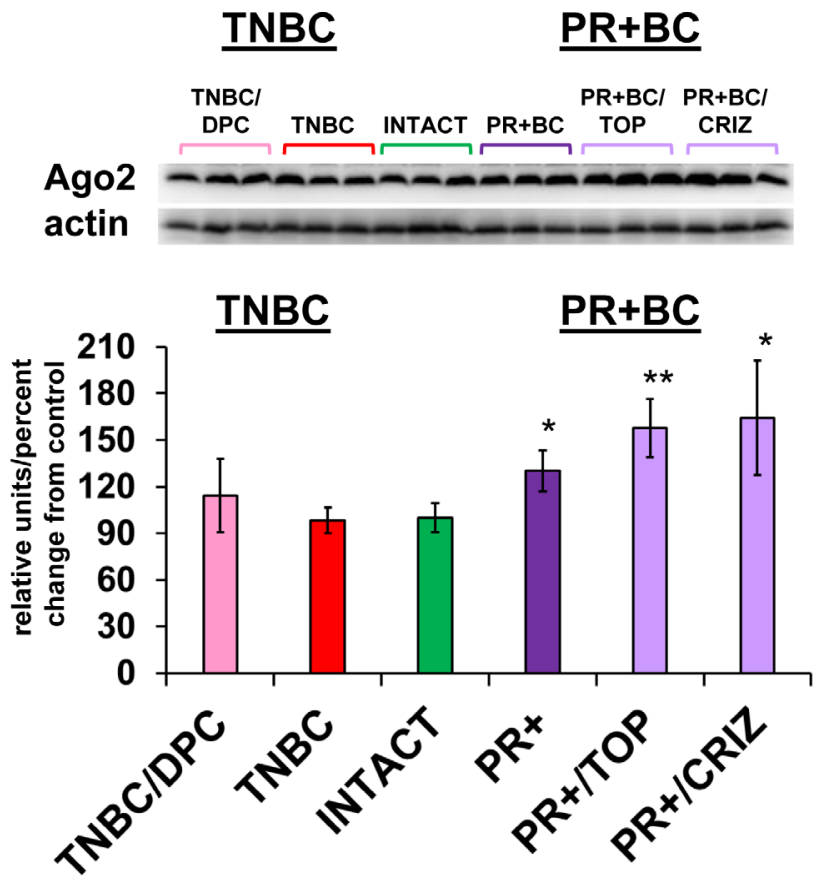

Figure 6: Levels of Dicer and Ago2 in the PFC tissues of intact and TNBC and PR+BC-bearing chemotherapy treated and untreated TumorGraft mice. Data are shown as relative units/percent change from control. Due to protein size differences and scarcity of tissue membranes were re-used several times in context of a large scale study. ${ }^{*} p<0.05 ; * * p<0.01$. 
reported the role of miR-191-5p in systemic inflammatory response syndrome [59]. Based on that, a potential next step is analyzing the links, if any, between miR-191-5p expression and inflammation in chemo brain and tumor brain - especially in light of evidence revealing the role of inflammation in chemo brain [60].

Along with miR-191-5p, miR-100-5p was upregulated in TNBC animals and TNBC/DCP animals, as compared to intact controls. Recently, miR-100-5p was shown to be an upregulated circulating marker of Huntington's disease [61]. Furthermore, this miRNA was said to be involved in the amyloid $\beta$-induced pathologes [62], whereby, along with miR-99b-5p, it affected neuronal survival by targeting PI3K/Akt/mTOR. In Alzheimer's disease (AD), miR-100-5p was downregulated in the early-middle stages, , but upregulated at the late stages of the disease. Activation of PI3K/Akt signaling promotes neuron survival. Downregulation of miR-100-5p at the early stages of AD may protect neurons from amyloid $\beta$-induced apoptosis, while such protection can be lost at later stages when miR-100-5p gets upregulated [63]. More studies are needed to dissect the roles of miR-100-5p and $\mathrm{PI} 3 \mathrm{~K} / \mathrm{Akt} / \mathrm{mTOR}$ in tumor brain and chemo brain and how they relate to the changes induced by TNBC tumor growth and DCP treatment.

DCP treatment caused upregulation of the let-7 family miRNAs - let-7a, 7b, 7g, $7 \mathrm{i}$ - in the PFC tissues of TBNC mice, as compared to intact controls. These family members were also upregulated in the PFC tissues of PR+BC-untreated (let-7a, 7b, 7c, 7g, 7i) and PR+BC/ topotecan-treated mice (let 7a, 7b, 7c, 7d, 7e, 7g, 7i). The let-7 family is highly conserved in both invertebrates and vertebrates, and was the second such miRNA family to be identified and characterized [64]. Since the different let-7 family members have similar or even identical seed sequences, they likely have overlapping sets of target mRNAs. The let-7 family is one of the well-known tumorsuppressor miRNA families $[65,66]$ that target RAS $[67$, 68], a cellular oncogene. Many tumors exhibit profound downregulation of let-7 [69], and the overexpression of let-7 strongly suppresses tumor cell growth. Let-7 levels are usually low in undifferentiated cells. In lung cancer, low let-7 levels are correlated with poor survival [70].

The let-7 family is involved in neural development and neuronal differentiation $[24,71]$. In the brain, let7 levels have been shown to increase after cerebral

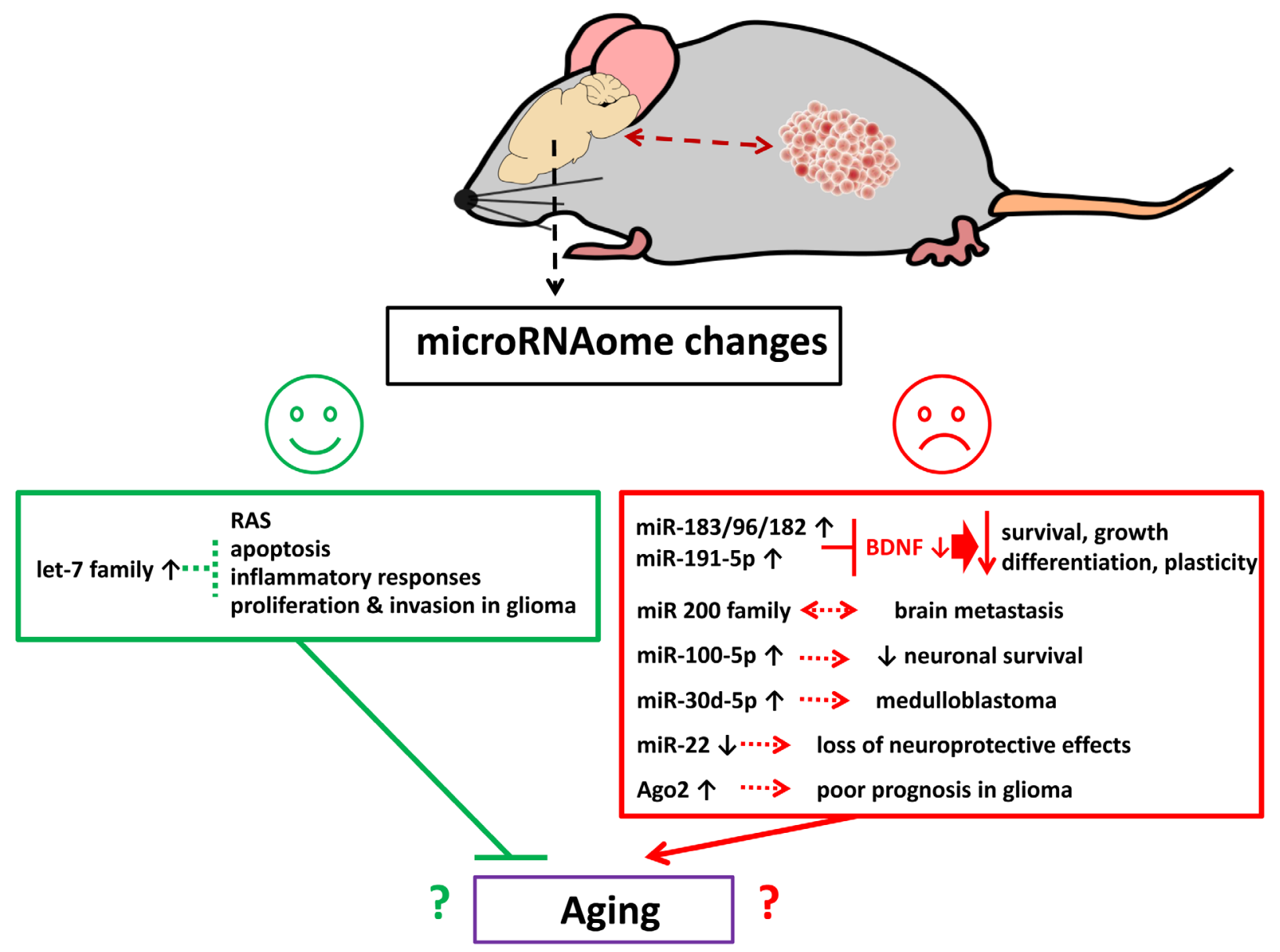

Figure 7: Schematic representation of possible biological effects of tumor brain and chemo brain-induced miRNAome changes in the brain. 
ischemia/reperfusion injury $[72,73]$, whereas let7 suppression inhibited apoptosis and inflammatory responses and caused an overall neuroprotective effect upon cerebral ischemia/reperfusion injury [73]. In a rat model of a middle cerebral artery occlusion and subsequent reperfusion injury, let-7 family members were upregulated at the 48-hour reperfusion time point [72, 74]. In $C$. elegancs, several neurons have shown increased levels of let-7 as they age, whereby let-7 upregulation contributed to the decline of aging neurons' regeneration potential [75]. Let-7 microRNAs was downregulated in radiation-exposed neural granule cell progenitors, as well as in medulloblastoma [76]. Several other studies have shown radiation-induced downregulation of let-7 family members in cells and tissues, and this downregulation was associated with the altered expression of the DNA damage mediator protein p53 [77, 78]. The let-7 family is also involved in glioma, where the upregulation of let- $7 \mathrm{~b}$ inhibited proliferation, migration and invasion in glioma cell lines. Furthermore, increased levels of let- $7 \mathrm{~b}$ reduced the stemness of glioma stem-like cells [79]. Overall, upregulation of the let-7 family may viewed as a positive and protective event in the context of cancer and brain metastasis, whereby it acts as a tumor-suppressor and blocks proliferation. Contrarily, in the context of some brain diseases and damage, it may have negative effects as well, as glial proliferation is important in repairing tissue damage. In the future, more studies are needed to dissect the cellular, tissue-specific, and behavioral repercussions of let-7 upregulation in tumor brain and chemo brain.

The most pronounced miRNAome changes were observed in the $\mathrm{PR}+\mathrm{BC}$ group. $\mathrm{PR}+\mathrm{BC}$ tumor growth and subsequent chemotherapy treatment with topotecan and crizotinib had profound effects on the miRNAome of TumorGraft animals' PFC tissue. Both tumor growth and chemotherapy treatment led to the upregulation of the miR-200 family, as compared to intact animals. We observed the upregulation of eight miRNAs that make up a related miR-200 family (miR-200a, 200b, 200c, miR141, miR-429) and a miR-183/96/182 cluster. These miRNAs are often co-transcribed and referred to as the miR-200/182 cluster. It was shown the entire miR-200/182 cluster is upregulated in acute herpes simplex virus 1 encephalitis [80].

The miR-200 family is important for the proper balance between neuronal proliferation and differentiation during development [81]. Its aberrant expression has been associated with various types of malignant tumors [82], and was correlated with drug resistance and patients' overall survival [83]. A recent study analyzed and compared the miRNA profiles of gastric adenocarcinomas and brain metastatic carcinomas and identified the upregulation of, among others, the miR-200 family members miR-141-3p and miR-200b-3p in the brain metastatic samples [84]. Therefore, deregulation of the miR-200 family could be involved in brain metastasis via the Zeb/miR-200 family feedback loop. Overall, much remains to be discovered about the miR-200 family's roles in various diseases and conditions, including cancer and cancer treatment-associated CNS toxicity. The miR-183/96/182 cluster upregulated in the PR+BC tumor-bearing treated and untreated mice was implicated in hepatocellular carcinoma, breast cancer, and glioma [85-87]. It has also been linked with light-induced retinal injury and was shown to target brain-derived neurotrophic factor (BDNF) [53]. BDNF is also a target of miR-191 that was upregulated in all experimental animal groups, as compared to controls [51].

The negative correlation between the levels of miRNAs that target BDNF and the levels of BDNF protein constitutes an interesting and important finding. We noted that BDNF levels were strongly downregulated in $\mathrm{PR}+\mathrm{BC}$ tumor-bearing treated and untreated animals; however, TNBC treated and untreated animals exhibited only a trend. BDNF, along with the nerve growth factors neurotrophin-3 and neurotrophin- $4 / 5$, is a member of the neurotrophin family [88]. BDNF is a key regulator of neural development, survival, growth, differentiation and plasticity $[89,90]$ because of its involvement in controlling the expression of pro-survival and anti-apoptosis genes [88]. Furthermore, BDNF is known to modulate synaptic function and plasticity, and is involved in learning and memory [88]. Deletion of the BDNF gene causes dendritic degeneration and neuronal loss, and decreased BDNF levels are associated with cognitive impairments in patients with Parkinson's disease [91], Alzheimer's disease [92], depression, and many other neurological and psychiatric disorders. A missense mutation in BDNF was shown to alter cognitive performance post-traumatic brain injury [93]. As one of the main neurotrophic factors, BDNF constitutes a promising remedy for reducing neuronal injury after cerebral ischemia [94] and for functional recovery in ALS [95].

It was reported that depression, which might be a manifestation of tumor brain and chemo brain in cancer patients, is often associated with reduced BDNF serum levels $[96,97]$. Low levels of BDNF in cancer patients were connected with depression and poor prognosis ${ }^{96}$. However, an animal model-based study of doxorubicin and cyclophosphamide chemotherapy-induced chemo brain showed that behavioral deficits (anxiety and spatial cognition impairments) were paralleled by decreased neurogenesis and lowered serum BDNF levels without alterations to BDNF, mRNA, or protein levels in the brain [98]. In our study, we saw significant downregulation of $\mathrm{BDNF}$ in $\mathrm{PR}+\mathrm{BC}$ tumor-bearing treated and untreated mice and a trend towards downregulation in tumor-bearing TNBC animals. Hence, BDNF downregulation may be due to the presence of non-CNS malignant tumors, rather than chemotherapy treatment itself. In context of previous studies, BDNF down-regulation may have negative consequences for both brain and behaviour. Going 
forward, we would seek to examine the mechanisms of tumor and chemotherapy-induced effects on BDNF levels in conjunction with miRNA. And, in addition, analyze the mechanisms regulating miRNA expression in the brains of tumor-bearing treated and untreated animals, as well as the neuroanatomical and behavioral repercussions of tumor and chemo brain-associated BDNF downregulation. Furthermore, it would be important to establish and compare the roles of tumor growth and chemotherapy in BDNF regulation, and analyze BDNF regulation as a function of malignant tumor load. As such, successful chemotherapy leads to a reduced tumor load, which by itself may affect BDNF levels.

While we did not see any changes in the Dicer levels, we noted a significant upregulation in the levels of Ago 2 in the PFC tissues of $\mathrm{PR}+\mathrm{BC}$ tumor-bearing treated and untreated animals. Elevated Ago2 levels may, in turn, contribute to the more profound changes in miRNA expression observed in the $\mathrm{PR}+\mathrm{BC}$ groups. Upregulation of the Ago2, protein that partakes miRNA production and execution of miRNA-mediated gene silencing was implicated in the regulation of cocaine addiction and anorexia [99]. Moreover, increased levels of Ago2 conveyed very poor prognosis in glioma [100]. The mechanisms of Ago2 upregulation and its repercussions in tumor brain and chemo brain need to be further studied.

Here we focused on tumor brain and chemo brain as induced by the growth of TNBC and PR+BC tumors, both stage IV. In the future, it would be prudent to look at the miRNAome as a function of tumor stage and grade, as well as to analyse miRNAome deregulation caused by other tumor types. Additionally, we focused our attentions on the PFC; however, previous studies have suggested chemo brain also manifests in the hippocampus [98]. Therefore, it would be interesting to analyze the brain region specificity of chemo brain and tumor brain and to correlate those findings with the roles of miRNAs.

In sum, growth of malignant $\mathrm{TNBC}$ and $\mathrm{PR}+\mathrm{BC}$ tumors altered the miRNAome of tumor bearing treated and untreated animals' PFC. The observed changes may have opposing functional consequences - some positive and protective and some, negative and deleterious. Among altered miRNAs, miR-183/96/182 cluster and miR-191-5p both target and downregulate BDNF. Here their increased expression was paralleled by a decrease in BDNF. Low BDNF levels have been shown to decrease neuronal survival, growth, differentiation and plasticity, and were reported in a wide array of neurological diseases and conditions. Meanwhile, miR-22 is a wellstudied neuroprotective molecule [101] and its observed downregulation may have detrimental consequences for cells. The miR-200 family was associated with brain metastases [84], and miR-30d-5p was implicated in medulloblastoma development [102]. Furthermore, Ago2 protein upregulation is a very negative glioma prognostic factor [100] (Figure 7).
Some of the observed miRNA changes could be associated with cellular senescence and aging. Amongst these, oxidative stress-induced upregulation of the miR-200 family caused senescence [103]., and stressinduced cellular senescence was also promoted by the miR-183/96/182 cluster [104]. MiR-191-5p is one of the biomarkers of aging-associated Alzheimer's disease. These miRNAs therefore ought to be explored as potential drivers of aging processes. On the other hand, the let-7 family includes many potent senescence-inhibiting and anti-age miRNAs [105]. Overall, there may be complex interplay between miRNA-mediated pro-and antisenescence pathways and processes in the PFC tissues of tumor-bearing animals. The precise nature, regulation, and organismal and behavioral repercussions of altered expression in these miRNA families and clusters needs to be looked (Figure 7).

For a bigger picture of tumor brain and chemo brain's mechanisms, we would proceed with identifying molecular pathways that were aberrantly expressed and regulated by miRNAs As such, it would be prudent to analyse the mechanisms, timing, and potential feedback loops between miRNA and mRNA regulation and expression, and integrate transcriptome, small RNAome, as well as methylome. More studies are needed to dissect the effects of miRNAs on signalling pathways and to discern the interplay between the various signalling pathways underlying tumor brain and chemo brain in the context of the entire signalome and interactome, as well as their functional outcomes. We focused on miRNAs, molecules that constitute the largest proportion of differentially regulated small RNAs. In the future, we would seek to analyze the roles of other small RNA molecules, such as tRNAs, snoRNAs, snRNA and others. These could prove to be important tumor brain and chemo brain biomarkers. In summary, this study is the first to show miRNAome deregulation in tumor brain and chemo brain, and may serve as a roadmap for further analysis of cancer and chemotherapy's neural side effects. In the future, in order to gain a full understanding of tumor brain and chemo brain, molecular and cellular data need to be put in context of neuronal structure analysis and behavioral changes.

\section{MATERIALS AND METHODS}

\section{Animal model}

We used the well-established TumorGraft technology developed by Champions Oncology, Inc. (Baltimore, $\mathrm{MD})$; the frozen brain tissues of TumorGraft mice carrying TNBC and $\mathrm{PR}+\mathrm{BC}$ patient-derived xenografts (PDX) were provided by Champions Oncology, Inc. Patients diagnosed with $\mathrm{TNBC}$ and $\mathrm{PR}+\mathrm{BC}$ had their tumors engrafted 
into mice to generate personalized TumorGraft mouse models for precision oncology approaches. The patients provided their informed consent, which covered the use of tumor material for research purposes. TumorGrafts were generated, as previously described [106-110]. In brief, a fresh specimen of the tumor is obtained during surgery, and small fragments of the tumor containing malignant cells and supportive stromal components are inserted subcutaneously into the flanks of six-week-old immunodeficient female mice (female $n u / n u$ athymic mice; Harlan Laboratories, Indianapolis, IND) and further propagated as earlier described. Animal experiments were approved by Institutional Animal Care and Use Committee protocols. Following tumor propagation, when TumorGrafts grew larger than $200 \mathrm{~mm}^{3}$, the animals were divided into groups of three to five. Drug dosage and drug combinations were applied consistent with individual physicians' recommendations and in consultation with the patient. The starting volumes differed between individual TumorGraft models because of the varying doubling time involved. As per agreed protocol, TNBC PDX-bearing TumorGraft animals were treated with Doxorubicin/Paclitaxel/Cyclophosphamide $(n=4$ treated and 4 untreated), and $\mathrm{PR}+\mathrm{BC}$ animals with Topotecan $(\mathrm{PR}+\mathrm{BC} / \mathrm{TOP})$ or Crizotinib $(\mathrm{PR}+\mathrm{BC} / \mathrm{CRIZ})(n=3$ treated and untreated). Intact animals (no tumour, no treatment, $n=3$ ) served as baseline controls. The aforementioned chemotherapy agents were prepared according to the manufacturer's specifications, and Champions Oncology ran all chemotherapy treatments. Tumor growth was strictly monitored; tumor dimensions were regularly measured and tumor volumes were calculated as previously described [110]. In both cases, chemotherapy applications resulted in successful tumor suppression and reduction of tumor growth (data not shown). Animals were humanely sacrificed; the brains were removed and immediately frozen in liquid nitrogen and stored in $-80{ }^{\circ} \mathrm{C}$ for molecular analysis. The tissues were split to accommodate DNA, RNA, and protein analysis.

\section{Total RNA isolation and small RNA sequencing}

Small RNA sequencing was conducted using Illumina next generation sequencing technology as previously described [111]. In brief, total RNA from the PFC tissues was isolated using the RecoverAll Total Nucleic Acid Isolation Kit (Life Technologies). RNA quality and quantity were analyzed with Bioanalyzer 2100 and RNA Nano Chips (Agilent Technologies). Small RNAs were sequenced using TruSeq Small RNA Sequencing Kit (Illumina), TruSeq SR Cluster Kit v5CS-GA (Illumina) and TruSeq SBS Kit v5-GA (Illumina) according to manufacturer's instructions. All the samples were sequenced on the Illumina Next 500 sequencer using the 36-cycle single-end protocol. Base calling and demultiplexing were done using CASAVA 1.8.2 with default settings, followed by trimming of adapters using Cutadapt version 1.8.dev0 ( https://cutadapt.readthedocs. io/en/stable/ ). The quality of the sequenced reads after adapter trimming was assessed using FASTQC software (http://www.bioinformatics.babraham.ac.uk/projects/

fastqc/). The bowtie v.1.1.2 version [112] was used to map the reads to the reference mouse genome (UCSC mm10 genome assembly). Trimmed reads were sequentially mapped to various small classes (miRNAs, snRNA, rRNA, snoRNA, tRNAs) and genomic features (repeats, exons and introns), reads that did not map to any of small RNAs or other genomic features were considered unclassified. Further analysis focused on miRNA group. To detect differentially expressed small RNAs. Raw counts of unique tags were loaded in R. Normalization and the detection of differentilly expressed tags was done using DESeq2 Bioconductor package [113]. Multiple comparisons adjustment was done with BenjaminiHochberg procedure.

\section{Western immunoblotting}

Western immunoblotting was conducted as previously described [114-117]. In brief, around 50 $\mathrm{mg}$ of PFC tissues were sonicated in ice-cold 1\% SDS and immediately boiled. Protein concentrations were determined using the Bradford assay (BioRad, Hercules, CA). Equal amounts of protein $(10-30 \mu \mathrm{g})$ were separated by SDS-PAGE into slab gels of $10-15 \%$ polyacrylamide and transferred to polyvinylidene difluoride membranes (Amersham Biosciences, Baie d'Urfé, Quebec). Eight membranes were prepared in total. Due to scarce amount of tissues, membranes were re-used and re-probed to allow for analysis of miRNA machinery and targets (this study), as well as epigenetic regulators (Kovalchuk et al., 2017, Aging, in press). The membranes were incubated with primary antibodies against BDNF, Dicer and Ago2 (1:1000, Abcam), and actin (1:2000, Abcam) overnight at $4^{\circ} \mathrm{C}$. Primary antibody binding was detected using horseradish peroxidase-conjugated secondary antibodies and the Enhanced Chemiluminescence Plus System (Amersham Biosciences, Baie d'Urfé, Quebec). Chemiluminescence was detected using a FluorChem HD2 camera with FluorChem software (Cell Biosciences). The membranes were stained with Coomassie blue (BioRad, Hercules, CA) to confirm equal protein loading. Signals were quantified using NIH Image J64 software and normalised relative to actin or Coomassie staining.

\section{Statistical analyses}

Statistical analysis (Student's t-test) was performed using the Microsoft Excel software package. 


\section{ACKNOWLEDGMENTS}

We thank Rommy Rodriguez-Juarez, Araba Sagoe, and Andrey Golubov for their technical support. Anna Kovalchuk was a recipient of the Alberta Cancer Foundation Dr. Cyril Kay Graduate Scholarship, Alberta Innovates-Health Solutions and Canada Vanier Graduate Scholarship. The research has been supported by a Canadian Institutes of Health Research grant held by Olga Kovalchuk and Bryan Kolb.

\section{CONFLICTS OF INTEREST}

The authors declare no conflict of interest.

\section{REFERENCES}

1. Andreotti C, Root JC, Schagen SB, McDonald BC, Saykin AJ, Atkinson TM, Li Y, Ahles TA. Reliable change in neuropsychological assessment of breast cancer survivors. Psychooncology. 2016; 25:43-50.

2. Ahles TA, Saykin AJ, Furstenberg CT, Cole B, Mott LA, Skalla K, Whedon MB, Bivens S, Mitchell T, Greenberg ER, Silberfarb PM. Neuropsychologic impact of standarddose systemic chemotherapy in long-term survivors of breast cancer and lymphoma. J Clin Oncol. 2002; 20:485493.

3. Kaiser J, Bledowski C, Dietrich J. Neural correlates of chemotherapy-related cognitive impairment. Cortex. 2014; 54:33-50.

4. Vardy J, Tannock I. Cognitive function after chemotherapy in adults with solid tumours. Crit Rev Oncol Hematol. 2007; 63:183-202.

5. Ahles TA. Brain vulnerability to chemotherapy toxicities. Psychooncology. 2012; 21:1141-1148.

6. Koppelmans V, Breteler MM, Boogerd W, Seynaeve C, Gundy C, Schagen SB. Neuropsychological performance in survivors of breast cancer more than 20 years after adjuvant chemotherapy. J Clin Oncol. 2012; 30:1080-1086.

7. Koppelmans V, de Groot M, de Ruiter MB, Boogerd W, Seynaeve C, Vernooij MW, Niessen WJ, Schagen SB, Breteler MM. Global and focal white matter integrity in breast cancer survivors 20 years after adjuvant chemotherapy. Hum Brain Mapp. 2014; 35:889-899.

8. Koppelmans V, de Ruiter MB, van der Lijn F, Boogerd W, Seynaeve C, van der Lugt A, Vrooman H, Niessen WJ, Breteler MM, Schagen SB. Global and focal brain volume in long-term breast cancer survivors exposed to adjuvant chemotherapy. Breast Cancer Res Treat. 2012; 132:10991106.

9. Olson K, Hewit J, Slater LG, Chambers T, Hicks D, Farmer A, Grattan K, Steggles S, Kolb B. Assessing cognitive function in adults during or following chemotherapy: a scoping review. Support Care Cancer. 2016; 24:3223-3234.
10. Yang M, Kim JS, Kim J, Jang S, Kim SH, Kim JC, Shin $\mathrm{T}$, Wang $\mathrm{H}$, Moon C. Acute treatment with methotrexate induces hippocampal dysfunction in a mouse model of breast cancer. Brain research bulletin. 2012; 89:50-56.

11. Wefel JS, Vardy J, Ahles T, Schagen SB. International Cognition and Cancer Task Force recommendations to harmonise studies of cognitive function in patients with cancer. Lancet Oncol. 2011; 12:703-708.

12. Myers JS. Neuropsychologic testing for chemotherapyrelated cognitive impairment. Adv Exp Med Biol. 2010; 678:55-69.

13. Seigers R, Fardell JE. Neurobiological basis of chemotherapy-induced cognitive impairment: a review of rodent research. Neurosci Biobehav Rev. 2011; 35:729-741.

14. Seigers R, Loos M, Van Tellingen O, Boogerd W, Smit AB, Schagen SB. Cognitive impact of cytotoxic agents in mice. Psychopharmacology (Berl). 2015; 232:17-37.

15. Myers JS, Pierce J, Pazdernik T. Neurotoxicology of chemotherapy in relation to cytokine release, the bloodbrain barrier, and cognitive impairment. Oncol Nurs Forum. 2008; 35:916-920.

16. Mustafa S, Walker A, Bennett G, Wigmore PM. 5-Fluorouracil chemotherapy affects spatial working memory and newborn neurons in the adult rat hippocampus. Eur J Neurosci. 2008; 28:323-330.

17. Joshi G, Aluise CD, Cole MP, Sultana R, Pierce WM, Vore M, St Clair DK, Butterfield DA. Alterations in brain antioxidant enzymes and redox proteomic identification of oxidized brain proteins induced by the anti-cancer drug adriamycin: implications for oxidative stress-mediated chemobrain. Neuroscience. 2010; 166:796-807.

18. Briones TL, Woods J. Chemotherapy-induced cognitive impairment is associated with decreases in cell proliferation and histone modifications. BMC Neurosci. 2011; 12:124.

19. Christie LA, Acharya MM, Parihar VK, Nguyen A, Martirosian V, Limoli CL. Impaired cognitive function and hippocampal neurogenesis following cancer chemotherapy. Clin Cancer Res. 2012; 18:1954-1965.

20. Myers JS. Chemotherapy-related cognitive impairment: the breast cancer experience. Oncol Nurs Forum. 2012; 39:E3140.

21. Wang XM, Walitt B, Saligan L, Tiwari AF, Cheung CW, Zhang ZJ. Chemobrain: a critical review and causal hypothesis of link between cytokines and epigenetic reprogramming associated with chemotherapy. Cytokine. 2015; 72:86-96.

22. Radhakrishnan B, Alwin Prem Anand A. Role of miRNA-9 in Brain Development. J Exp Neurosci. 2016; 10:101-120.

23. Miska EA, Alvarez-Saavedra E, Townsend M, Yoshii A, Sestan N, Rakic P, Constantine-Paton M, Horvitz HR. Microarray analysis of microRNA expression in the developing mammalian brain. Genome Biol. 2004; 5:R68.

24. Sempere LF, Freemantle S, Pitha-Rowe I, Moss E, Dmitrovsky E, Ambros V. Expression profiling of 
mammalian microRNAs uncovers a subset of brainexpressed microRNAs with possible roles in murine and human neuronal differentiation. Genome Biol. 2004; 5:R13.

25. Li P, Teng ZQ, Liu CM. Extrinsic and Intrinsic Regulation of Axon Regeneration by MicroRNAs after Spinal Cord Injury. Neural Plast. 2016; 2016:1279051.

26. Wang W, Kwon EJ, Tsai LH. MicroRNAs in learning, memory, and neurological diseases. Learn Mem. 2012; 19:359-368.

27. Bredy TW, Lin Q, Wei W, Baker-Andresen D, Mattick JS. MicroRNA regulation of neural plasticity and memory. Neurobiol Learn Mem. 2011; 96:89-94.

28. Saab BJ, Mansuy IM. Neuroepigenetics of memory formation and impairment: the role of microRNAs. Neuropharmacology. 2014; 80:61-69.

29. Hicks SD, Middleton FA. A Comparative Review of microRNA Expression Patterns in Autism Spectrum Disorder. Front Psychiatry. 2016; 7:176.

30. Karthikeyan A, Patnala R, Jadhav SP, Eng-Ang L, Dheen ST. MicroRNAs: Key Players in Microglia and Astrocyte Mediated Inflammation in CNS Pathologies. Curr Med Chem. 2016; 23:3528-3546.

31. Guedes J, Cardoso AL, Pedroso de Lima MC. Involvement of microRNA in microglia-mediated immune response. Clin Dev Immunol. 2013; 2013:186872.

32. Meydan C, Shenhar-Tsarfaty S, Soreq H. MicroRNA Regulators of Anxiety and Metabolic Disorders. Trends Mol Med. 2016; 22:798-812.

33. Koch MW, Metz LM, Kovalchuk O. Epigenetics and miRNAs in the diagnosis and treatment of multiple sclerosis. Trends Mol Med. 2013; 19:23-30.

34. Luoni A, Riva MA. MicroRNAs and psychiatric disorders: From aetiology to treatment. Pharmacol Ther. 2016; 167:13-27.

35. Lukiw WJ. Micro-RNA speciation in fetal, adult and Alzheimer's disease hippocampus. Neuroreport. 2007; 18:297-300.

36. Howng SY, Huang Y, Ptacek L, Fu YH. Understanding the role of dicer in astrocyte development. PLoS One. 2015; 10:e0126667.

37. Ristori E, Lopez-Ramirez MA, Narayanan A, Hill-Teran G, Moro A, Calvo CF, Thomas JL, Nicoli S. A Dicer-miR-107 Interaction Regulates Biogenesis of Specific miRNAs Crucial for Neurogenesis. Dev Cell. 2015; 32:546-560.

38. Saurat N, Andersson T, Vasistha NA, Molnar Z, Livesey FJ. Dicer is required for neural stem cell multipotency and lineage progression during cerebral cortex development. Neural Dev. 2013; 8:14.

39. Hebert SS, Papadopoulou AS, Smith P, Galas MC, Planel E, Silahtaroglu AN, Sergeant N, Buee L, De Strooper B. Genetic ablation of Dicer in adult forebrain neurons results in abnormal tau hyperphosphorylation and neurodegeneration. Hum Mol Genet. 2010; 19:3959-3969.

40. Fiorenza A, Barco A. Role of Dicer and the miRNA system in neuronal plasticity and brain function. Neurobiol Learn Mem. 2016; 135:3-12.

41. Jafari N, Shaghaghi H, Mahmoodi D, Shirzad Z, Alibeiki F, Bohlooli S, Dogaheh HP. Overexpression of microRNA biogenesis machinery: Drosha, DGCR8 and Dicer in multiple sclerosis patients. J Clin Neurosci. 2015; 22:200203.

42. Santarelli DM, Beveridge NJ, Tooney PA, Cairns MJ. Upregulation of dicer and microRNA expression in the dorsolateral prefrontal cortex Brodmann area 46 in schizophrenia. Biol Psychiatry. 2011; 69:180-187.

43. Pereira P, Queiroz JA, Figueiras A, Sousa F. Current progress on microRNAs-based therapeutics in neurodegenerative diseases. Wiley Interdiscip Rev RNA. 2016.

44. Martinez B, Peplow PV. Blood microRNAs as potential diagnostic and prognostic markers in cerebral ischemic injury. Neural Regen Res. 2016; 11:1375-1378.

45. Cosin-Tomas M, Antonell A, Llado A, Alcolea D, Fortea J, Ezquerra M, Lleo A, Marti MJ, Pallas M, Sanchez-Valle R, Molinuevo JL, Sanfeliu C, Kaliman P. Plasma miR-34a$5 \mathrm{p}$ and miR-545-3p as Early Biomarkers of Alzheimer's Disease: Potential and Limitations. Mol Neurobiol. 2017; 54:5550-5562.

46. Zeng Y, Liu JX, Yan ZP, Yao XH, Liu XH. Potential microRNA biomarkers for acute ischemic stroke. Int J Mol Med. 2015; 36:1639-1647.

47. Koturbash I, Zemp F, Kolb B, Kovalchuk O. Sex-specific radiation-induced microRNAome responses in the hippocampus, cerebellum and frontal cortex in a mouse model. Mutat Res. 2011; 722:114-118.

48. Dasdag S, Akdag MZ, Erdal ME, Erdal N, Ay OI, Ay ME, Yilmaz SG, Tasdelen B, Yegin K. Effects of $2.4 \mathrm{GHz}$ radiofrequency radiation emitted from Wi-Fi equipment on microRNA expression in brain tissue. Int J Radiat Biol. 2015; 91:555-561.

49. Deng Y, Ai J, Guan X, Wang Z, Yan B, Zhang D, Liu C, Wilbanks MS, Escalon BL, Meyers SA, Yang MQ, Perkins EJ. MicroRNA and messenger RNA profiling reveals new biomarkers and mechanisms for RDX induced neurotoxicity. BMC Genomics. 2014; 15:S1.

50. Liu J, Jennings SF, Tong W, Hong H. Next generation sequencing for profiling expression of miRNAs: technical progress and applications in drug development. J Biomed Sci Eng. 2011; 4:666-676.

51. Varendi K, Kumar A, Harma MA, Andressoo JO. miR-1, miR-10b, miR-155, and miR-191 are novel regulators of BDNF. Cell Mol Life Sci. 2014; 71:4443-4456.

52. Hohn A, Leibrock J, Bailey K, Barde YA. Identification and characterization of a novel member of the nerve growth factor/brain-derived neurotrophic factor family. Nature. 1990; 344:339-341.

53. Li H, Gong Y, Qian H, Chen T, Liu Z, Jiang Z, Wei S. Brain-derived neurotrophic factor is a novel target gene of 
the has-miR-183/96/182 cluster in retinal pigment epithelial cells following visible light exposure. Mol Med Rep. 2015; 12:2793-2799.

54. Kim J, Inoue K, Ishii J, Vanti WB, Voronov SV, Murchison E, Hannon G, Abeliovich A. A MicroRNA feedback circuit in midbrain dopamine neurons. Science. 2007; 317:12201224.

55. Lara AH, Wallis JD. The Role of Prefrontal Cortex in Working Memory: A Mini Review. Front Syst Neurosci. 2015; 9:173.

56. Kolb B, Mychasiuk R, Muhammad A, Li Y, Frost DO, Gibb R. Experience and the developing prefrontal cortex. Proc Natl Acad Sci U S A. 2012; 109:17186-17193.

57. Mendes-Silva AP, Pereira KS, Tolentino-Araujo GT, Nicolau Ede S, Silva-Ferreira CM, Teixeira AL, Diniz BS. Shared Biologic Pathways Between Alzheimer Disease and Major Depression: A Systematic Review of MicroRNA Expression Studies. Am J Geriatr Psychiatry. 2016; 24:903912.

58. Kumar S, Reddy PH. Are circulating microRNAs peripheral biomarkers for Alzheimer's disease? Biochim Biophys Acta. 2016; 1862:1617-1627.

59. Caserta S, Kern F, Cohen J, Drage S, Newbury SF, Llewelyn MJ. Circulating Plasma microRNAs can differentiate Human Sepsis and Systemic Inflammatory Response Syndrome (SIRS). Sci Rep. 2016; 6:28006.

60. Cheung YT, Ng T, Shwe M, Ho HK, Foo KM, Cham MT, Lee JA, Fan G, Tan YP, Yong WS, Madhukumar P, Loo SK, Ang SF, et al. Association of proinflammatory cytokines and chemotherapy-associated cognitive impairment in breast cancer patients: a multi-centered, prospective, cohort study. Ann Oncol. 2015; 26:1446-1451.

61. Diez-Planelles C, Sanchez-Lozano P, Crespo MC, GilZamorano J, Ribacoba R, Gonzalez N, Suarez E, MartinezDescals A, Martinez-Camblor P, Alvarez V, MartinHernandez R, Huerta-Ruiz I, Gonzalez-Garcia I, et al. Circulating microRNAs in Huntington's disease: Emerging mediators in metabolic impairment. Pharmacol Res. 2016; 108:102-110.

62. Ye X, Luo H, Chen Y, Wu Q, Xiong Y, Zhu J, Diao Y, Wu Z, Miao J, Wan J. MicroRNAs 99b-5p/100-5p Regulated by Endoplasmic Reticulum Stress are Involved in AbetaInduced Pathologies. Front Aging Neurosci. 2015; 7:210.

63. Luo H, Wu Q, Ye X, Xiong Y, Zhu J, Xu J, Diao Y, Zhang D, Wang M, Qiu J, Miao J, Zhang W, Wan J. Genome-wide analysis of miRNA signature in the APPswe/PS1DeltaE9 mouse model of alzheimer's disease. PLoS One. 2014; 9:e101725.

64. Reinhart BJ, Slack FJ, Basson M, Pasquinelli AE, Bettinger JC, Rougvie AE, Horvitz HR, Ruvkun G. The 21-nucleotide let-7 RNA regulates developmental timing in Caenorhabditis elegans. Nature. 2000; 403:901-906.

65. Esquela-Kerscher A, Trang P, Wiggins JF, Patrawala L, Cheng A, Ford L, Weidhaas JB, Brown D, Bader AG, Slack
FJ. The let-7 microRNA reduces tumor growth in mouse models of lung cancer. Cell Cycle. 2008; 7:759-764.

66. Kumar MS, Erkeland SJ, Pester RE, Chen CY, Ebert MS, Sharp PA, Jacks T. Suppression of non-small cell lung tumor development by the let-7 microRNA family. Proc Natl Acad Sci U S A. 2008; 105:3903-3908.

67. Johnson SM, Grosshans H, Shingara J, Byrom M, Jarvis R, Cheng A, Labourier E, Reinert KL, Brown D, Slack FJ. RAS is regulated by the let-7 microRNA family. Cell. 2005; 120:635-647.

68. Masliah-Planchon J, Garinet S, Pasmant E. RAS-MAPK pathway epigenetic activation in cancer: miRNAs in action. Oncotarget. 2016; 7:38892-38907. doi: 10.18632/ oncotarget.6476.

69. Boyerinas B, Park SM, Hau A, Murmann AE, Peter ME. The role of let-7 in cell differentiation and cancer. Endocr Relat Cancer. 2010; 17:F19-36.

70. Karube Y, Tanaka H, Osada H, Tomida S, Tatematsu Y, Yanagisawa K, Yatabe Y, Takamizawa J, Miyoshi S, Mitsudomi T, Takahashi T. Reduced expression of Dicer associated with poor prognosis in lung cancer patients. Cancer Sci. 2005; 96:111-115.

71. Aranha MM, Santos DM, Xavier JM, Low WC, Steer CJ, Sola S, Rodrigues CM. Apoptosis-associated microRNAs are modulated in mouse, rat and human neural differentiation. BMC Genomics. 2010; 11:514.

72. Jeyaseelan K, Lim KY, Armugam A. MicroRNA expression in the blood and brain of rats subjected to transient focal ischemia by middle cerebral artery occlusion. Stroke. 2008; 39:959-966.

73. Wang ZK, Liu FF, Wang Y, Jiang XM, Yu XF. Let-7a gene knockdown protects against cerebral ischemia/reperfusion injury. Neural Regen Res. 2016; 11:262-269.

74. Di Y, Lei Y, Yu F, Changfeng F, Song W, Xuming M. MicroRNAs expression and function in cerebral ischemia reperfusion injury. J Mol Neurosci. 2014; 53:242-250.

75. Ivakhnitskaia E, Hamada K, Chang C. Timing mechanisms in neuronal pathfinding, synaptic reorganization, and neuronal regeneration. Dev Growth Differ. 2016; 58:88-93.

76. Tanno B, Babini G, Leonardi S, Giardullo P, De Stefano I, Pasquali E, Ottolenghi A, Atkinson MJ, Saran A, Mancuso M. Ex vivo miRNome analysis in Ptch1+/- cerebellum granule cells reveals a subset of miRNAs involved in radiation-induced medulloblastoma. Oncotarget. 2016; 7:68253-68269. doi: 10.18632/oncotarget.11938.

77. Saleh AD, Savage JE, Cao L, Soule BP, Ly D, DeGraff W, Harris CC, Mitchell JB, Simone NL. Cellular stress induced alterations in microRNA let-7a and let-7b expression are dependent on p53. PLoS One. 2011; 6:e24429.

78. Weidhaas JB, Babar I, Nallur SM, Trang P, Roush S, Boehm M, Gillespie E, Slack FJ. MicroRNAs as potential agents to alter resistance to cytotoxic anticancer therapy. Cancer Res. 2007; 67:11111-11116.

79. Song H, Zhang Y, Liu N, Zhang D, Wan C, Zhao S, Kong 
Y, Yuan L. Let-7b inhibits the malignant behavior of glioma cells and glioma stem-like cells via downregulation of E2F2. J Physiol Biochem. 2016; 72:733-744.

80. Majer A, Caligiuri KA, Gale KK, Niu Y, Phillipson CS, Booth TF, Booth SA. Induction of Multiple miR-200/182 Members in the Brains of Mice Are Associated with Acute Herpes Simplex Virus 1 Encephalitis. PLoS One. 2017; 12:e0169081.

81. Pandey A, Singh P, Jauhari A, Singh T, Khan F, Pant AB, Parmar D, Yadav S. Critical role of the miR-200 family in regulating differentiation and proliferation of neurons. J Neurochem. 2015; 133:640-652.

82. Zuberi M, Mir R, Das J, Ahmad I, Javid J, Yadav P, Masroor M, Ahmad S, Ray PC, Saxena A. Expression of serum miR-200a, miR-200b, and miR-200c as candidate biomarkers in epithelial ovarian cancer and their association with clinicopathological features. Clin Transl Oncol. 2015; 17:779-787.

83. Senfter D, Madlener S, Krupitza G, Mader RM. The microRNA-200 family: still much to discover. Biomol Concepts. 2016; 7:311-319.

84. Korpal M, Lee ES, Hu G, Kang Y. The miR-200 family inhibits epithelial-mesenchymal transition and cancer cell migration by direct targeting of E-cadherin transcriptional repressors ZEB1 and ZEB2. J Biol Chem. 2008; 283:1491014914.

85. Leung WK, He M, Chan AW, Law PT, Wong N. Wnt/ beta-Catenin activates MiR-183/96/182 expression in hepatocellular carcinoma that promotes cell invasion. Cancer Lett. 2015; 362:97-105.

86. Tang H, Bian Y, Tu C, Wang Z, Yu Z, Liu Q, Xu G, Wu M, Li G. The miR-183/96/182 cluster regulates oxidative apoptosis and sensitizes cells to chemotherapy in gliomas. Curr Cancer Drug Targets. 2013; 13:221-231.

87. Li P, Sheng C, Huang L, Zhang H, Huang L, Cheng Z, Zhu Q. MiR-183/-96/-182 cluster is up-regulated in most breast cancers and increases cell proliferation and migration. Breast Cancer Res. 2014; 16:473.

88. Baydyuk M, Xu B. BDNF signaling and survival of striatal neurons. Front Cell Neurosci. 2014; 8:254.

89. Bondar NP, Merkulova TI. Brain-derived neurotrophic factor and early-life stress: Multifaceted interplay. J Biosci. 2016; 41:751-758.

90. Mitre M, Mariga A, Chao MV. Neurotrophin signalling: novel insights into mechanisms and pathophysiology. Clin Sci (Lond). 2017; 131:13-23.

91. Wang Y, Liu H, Zhang BS, Soares JC, Zhang XY. Low BDNF is associated with cognitive impairments in patients with Parkinson's disease. Parkinsonism Relat Disord. 2016; 29:66-71.

92. Song JH, Yu JT, Tan L. Brain-Derived Neurotrophic Factor in Alzheimer's Disease: Risk, Mechanisms, and Therapy. Mol Neurobiol. 2015; 52:1477-1493.

93. Narayanan V, Veeramuthu V, Ahmad-Annuar A, Ramli N,
Waran V, Chinna K, Bondi MW, Delano-Wood L, Ganesan D. Missense Mutation of Brain Derived Neurotrophic Factor (BDNF) Alters Neurocognitive Performance in Patients with Mild Traumatic Brain Injury: A Longitudinal Study. PLoS One. 2016; 11:e0158838.

94. Harris NM, Ritzel R, Mancini N, Jiang Y, Yi X, Manickam DS, Banks WA, Kabanov AV, McCullough LD, Verma R. Nano-particle delivery of brain derived neurotrophic factor after focal cerebral ischemia reduces tissue injury and enhances behavioral recovery. Pharmacol Biochem Behav. 2016; 150-151:48-56.

95. Shruthi S, Sumitha R, Varghese AM, Ashok S, Chandrasekhar Sagar BK, Sathyaprabha TN, Nalini A, Kramer BW, Raju TR, Vijayalakshmi K, Alladi PA. Brain-Derived Neurotrophic Factor Facilitates Functional Recovery from ALS-Cerebral Spinal Fluid-Induced Neurodegenerative Changes in the NSC-34 Motor Neuron Cell Line. Neurodegener Dis. 2017; 17:44-58.

96. Wu Y, Si R, Yang S, Xia S, He Z, Wang L, He Z, Wang Q, Tang H. Depression induces poor prognosis associates with the down-regulation brain derived neurotrophic factor of serum in advanced small cell lung cancer. Oncotarget. 2016; 7:85975-85986. doi: 10.18632/oncotarget.13291.

97. Jehn CF, Becker B, Flath B, Nogai H, Vuong L, Schmid P, Luftner D. Neurocognitive function, brain-derived neurotrophic factor (BDNF) and IL-6 levels in cancer patients with depression. J Neuroimmunol. 2015; 287:8892.

98. Kitamura Y, Hattori S, Yoneda S, Watanabe S, Kanemoto E, Sugimoto M, Kawai T, Machida A, Kanzaki H, Miyazaki I, Asanuma M, Sendo T. Doxorubicin and cyclophosphamide treatment produces anxiety-like behavior and spatial cognition impairment in rats: Possible involvement of hippocampal neurogenesis via brain-derived neurotrophic factor and cyclin D1 regulation. Behav Brain Res. 2015; 292:184-193.

99. Mercader JM, Gonzalez JR, Lozano JJ, Bak M, Kauppinen S, Sumoy L, Dierssen M, Fernandez-Aranda F, Visa J, Gratacos M, Estivill X. Aberrant brain microRNA target and miRISC gene expression in the anx/anx anorexia mouse model. Gene. 2012; 497:181-190.

100. Feng B, Hu P, Lu SJ, Chen JB, Ge RL. Increased argonaute 2 expression in gliomas and its association with tumor progression and poor prognosis. Asian Pac J Cancer Prev. 2014; 15:4079-4083.

101. Ma J, Shui S, Han X, Guo D, Li T, Yan L. microRNA-22 attenuates neuronal cell apoptosis in a cell model of traumatic brain injury. Am J Transl Res. 2016; 8:18951902.

102. Lu Y, Ryan SL, Elliott DJ, Bignell GR, Futreal PA, Ellison DW, Bailey S, Clifford SC. Amplification and overexpression of Hsa-miR-30b, Hsa-miR-30d and KHDRBS3 at 8q24.22-q24.23 in medulloblastoma. PLoS One. 2009; 4:e6159.

103. Magenta A, Cencioni C, Fasanaro P, Zaccagnini G, Greco 
S, Sarra-Ferraris G, Antonini A, Martelli F, Capogrossi MC. miR-200c is upregulated by oxidative stress and induces endothelial cell apoptosis and senescence via ZEB1 inhibition. Cell Death Differ. 2011; 18:1628-1639.

104. Li G, Luna C, Qiu J, Epstein DL, Gonzalez P. Alterations in microRNA expression in stress-induced cellular senescence. Mech Ageing Dev. 2009; 130:731-741.

105. Toledano $\mathrm{H}$. The role of the heterochronic microRNA let-7 in the progression of aging. Exp Gerontol. 2013; 48:667670.

106. Bertotti A, Migliardi G, Galimi F, Sassi F, Torti D, Isella C, Cora D, Di Nicolantonio F, Buscarino M, Petti C, Ribero D, Russolillo N, Muratore A, et al. A molecularly annotated platform of patient-derived xenografts ("xenopatients") identifies HER2 as an effective therapeutic target in cetuximab-resistant colorectal cancer. Cancer Discov. 2011; 1:508-523.

107. DeRose YS, Wang G, Lin YC, Bernard PS, Buys SS, Ebbert MT, Factor R, Matsen C, Milash BA, Nelson E, Neumayer L, Randall RL, Stijleman IJ, et al. Tumor grafts derived from women with breast cancer authentically reflect tumor pathology, growth, metastasis and disease outcomes. Nat Med. 2011; 17:1514-1520.

108. Hidalgo M, Bruckheimer E, Rajeshkumar NV, GarridoLaguna I, De Oliveira E, Rubio-Viqueira B, Strawn S, Wick MJ, Martell J, Sidransky D. A pilot clinical study of treatment guided by personalized tumorgrafts in patients with advanced cancer. Mol Cancer Ther. 2011; 10:13111316.

109. Morelli MP, Calvo E, Ordonez E, Wick MJ, Viqueira BR, Lopez-Casas PP, Bruckheimer E, Calles-Blanco A, Sidransky D, Hidalgo M. Prioritizing phase I treatment options through preclinical testing on personalized tumorgraft. J Clin Oncol. 2012; 30:e45-48.

110. Stebbing J, Paz K, Schwartz GK, Wexler LH, Maki R, Pollock RE, Morris R, Cohen R, Shankar A, Blackman G, Harding V, Vasquez D, Krell J, et al. Patient-derived xenografts for individualized care in advanced sarcoma. Cancer. 2014; 120:2006-2015.
111. Krishnan P, Ghosh S, Wang B, Li D, Narasimhan A, Berendt R, Graham K, Mackey JR, Kovalchuk O, Damaraju $\mathrm{S}$. Next generation sequencing profiling identifies miR-574$3 p$ and miR-660-5p as potential novel prognostic markers for breast cancer. BMC Genomics. 2015; 16:735.

112. Langmead B, Trapnell C, Pop M, Salzberg SL. Ultrafast and memory-efficient alignment of short DNA sequences to the human genome. Genome Biol. 2009; 10:R25.

113. Love MI, Huber W, Anders S. Moderated estimation of fold change and dispersion for RNA-seq data with DESeq2. Genome Biol. 2014; 15:550.

114. Silasi G, Diaz-Heijtz R, Besplug J, Rodriguez-Juarez R, Titov V, Kolb B, Kovalchuk O. Selective brain responses to acute and chronic low-dose X-ray irradiation in males and females. Biochem Biophys Res Commun. 2004; 325:12231235 .

115. Kovalchuk A, Mychasiuk R, Muhammad A, Hossain S, Ilnytskyy S, Ghose A, Kirkby C, Ghasroddashti E, Kovalchuk O, Kolb B. Liver irradiation causes distal bystander effects in the rat brain and affects animal behaviour. Oncotarget. 2016; 7:4385-4398. doi: 10.18632/ oncotarget.6596.

116. Kovalchuk A, Mychasiuk R, Muhammad A, Hossain S, Ilnytskyy Y, Ghose A, Kirkby C, Ghasroddashti E, Kolb B, Kovalchuk O. Profound and Sexually Dimorphic Effects of Clinically-Relevant Low Dose Scatter Irradiation on the Brain and Behavior. Front Behav Neurosci. 2016; 10:84.

117. Kovalchuk A, Rodriguez-Juarez R, Inytskyy Y, Byeon B, Shpyleva S, Melnyk S, Pogribny I, Kolb B, Kovalchuk O. Sex-specific effects of cytotoxic chemotherapy agents cyclophosphamide and mitomycin $\mathrm{C}$ on gene expression, oxidative DNA damage, and epigenetic alterations in the prefrontal cortex and hippocampus - an aging connection. Aging (Albany NY). 2016; 8:697-711. doi: 10.18632/ aging. 100920 . 